Artikel Penelitian

\title{
Korelasi Kadar Karboksihemoglobin terhadap Tekanan Darah Penduduk di Sekitar Terminal Bus Tirtonadi Surakarta
}

\author{
Wimpy*, Tri Harningsih
}

Program Studi DIII Analis Kesehatan, Sekolah Tinggi IImu Kesehatan Nasional, Sukoharjo, Jawa Tengah, Indonesia, 57552

\section{INFO ARTIKEL}

\section{Riwayat Artikel}

Diterima 7 Oktober 2019

Direvisi 30 Oktober 2019

Tersedia online 4 Desember 2019

*Email penulis korespondensi:
wimpy@stikesnas.ac.id

\section{ABSTRAK}

Carbon monoxide is a gas from incomplete combustion of fuel containing carbon. In high concentration on the blood stream, carbon monoxide is able to cause death. The affinity of hemoglobin for carbon monoxide is higher than that of oxygen. Blood clotting because of high concentration carbon monoxide in the blood can increase blood viscosity and causes vasoconstriction. This study aims to determine the correlation between carboxyhaemoglobin $(\mathrm{COHb})$ and blood pressure of the resident living around Tirtonadi Bus Station, Surakarta. The concentration of $\mathrm{COHb}$ was analyzed using UV-Vis Spectrophotometer. The $\mathrm{COHb}$ concentration of $\mathrm{A} 1, \mathrm{~A} 2, \mathrm{~A} 3, \mathrm{~A} 4, \mathrm{~A} 5, \mathrm{~A} 6, \mathrm{~A} 7, \mathrm{~A} 8, \mathrm{~A} 9, \mathrm{~A} 10$ samples was 6.51, $6.28,6.22,6.23,6.21,6.17,6.17,6.11,6.15$, and $6.12 \%$, respectively. The result of the test was analyzed by SPSS. The result of normality test does not show normal distribution data. Statistical analysis was conducted by using Spearman. There is a significant value of systole $(0.027)$ and diastole $(0.011)$. There is a correlation between $\mathrm{COHb}$ concentration and blood pressure of the resident living around Tirtonadi Bus Station, Surakarta.

Keywords: Carboxyhaemoglobin, blood pressure, Tirtonadi bus station

Karbon monoksida adalah gas polutan yang berasal dari produk pembakaran yang tidak sempurna dari bahan bakar yang mengandung karbon. Pada konsentrasi tinggi dalam darah, gas ini dapat menyebabkan kematian. Afinitas karbon monoksida lebih besar dari pada dengan oksigen. Kadar karbon monoksida yang tinggi di dalam aliran darah akan membentuk bekuan darah sehingga akan meningkatkan kekentalan darah. Hal ini dapat menyebabkan terjadinya vasokonstriksi sehingga akan menaikan tekanan darah. Tujuan penelitian ini untuk mencari hubungan antara kadar karboksihemoglobin $(\mathrm{COHb})$ terhadap tekanan darah penduduk yang tinggal di sekitar Stasiun Bus Tirtonadi, Surakarta. Pengukuran kadar $\mathrm{COHb}$ menggunakan Spektrofotometer UV-Vis. Hasil uji kadar $\mathrm{COHb}$ pada kode sampel $\mathrm{A} 1, \mathrm{~A} 2, \mathrm{~A} 3, \mathrm{~A} 4, \mathrm{~A} 5, \mathrm{~A} 6, \mathrm{~A} 7, \mathrm{~A} 8, \mathrm{~A} 9$, dan $\mathrm{A} 10$ masingmasing sebesar 6,$51 ; 6,28 ; 6,22 ; 6,23 ; 6,21 ; 6,17 ; 6,17 ; 6,11 ; 6,15$ dan $6,12 \%$. Hasil data dianalisis dengan SPSS. Hasil uji normalitas tidak menunjukkan data distribusi normal. Pengukuran statistik dilakukan dengan menggunakan uji Spearman. Hasil penelitian menunjukkan nilai signifikan sistol sebesar 0,027 dan diastol sebesar 0,011 . Ada korelasi antara kadar $\mathrm{COHb}$ dengan tekanan darah pada penduduk yang tinggal di sekitar Terminal Tirtonadi, Surakarta.

Kata kunci: Karboksihemoglobin, tekanan darah, Terminal Tirtonadi 


\section{Pendahuluan}

Pencemaran udara yang berasal dari bahan toksik merupakan salah satu masalah kesehatan di dunia. Indonesia menjadi salah satu negara dengan tingkat pencemaran udara yang tinggi. Tujuh puluh persen gangguan kesehatan terjadi di daerah pencemaran yang tinggi seperti Jakarta, Medan, Batam, dan Solo [1]. Karbon monoksida (CO) merupakan salah satu bahan pencemar yang sangat berbahaya jika terhirup oleh manusia karena sifat fisiknya yang tidak berasa, tidak berwarna, dan tidak berbau, tetapi dalam konsentrasi yang tinggi dapat menyebabkan kematian pada manusia yang terpapar [2].

Gas CO berasal dari gas buangan mesin kendaraan, contohnya gas buangan mesin bus, mobil, motor, dan mesin pabrik. Gas $\mathrm{CO}$ yang terhirup terus menerus akan berpengaruh terhadap gangguan kesehatan, salah satunya adalah peningkatan tekanan darah. Penduduk yang tinggal di sekitar Terminal Bus Tirtonadi sangat rentan terpapar gas CO yang berasal dari asap buangan seperti dari bus, mobil, dan kendaraan bermotor yang beroperasi di Terminal Tirtonadi. Karbon monoksida memiliki afinitas dengan hemoglobin yang sangat kuat di dalam darah sehingga ketika tubuh terpapar dengan karbon monoksida, maka hemoglobin dalam darah akan membentuk ikatan dengan karbon monoksida yang disebut karboksihemoglobin $(\mathrm{COHb})$. Konsentrasi $\mathrm{COHb}$ yang meningkat dalam darah mengakibatkan peningkatan kekentalan darah sehingga mempermudah penggumpalan darah dan terjadi vasokonstriksi (penyempitan pembuluh darah) yang berdampak pada gangguan aliran darah. Gangguan aliran darah tersebut menyebabkan terjadinya peningkatan tekanan darah. Tekanan darah adalah tekanan yang dihasilkan oleh darah dari sistem sirkulasi atau sistem vaskuler terhadap dinding pembuluh darah [3].

Kategori tekanan darah menurut American Heart Association (AHA) tahun 2017 yaitu tekanan darah normal jika memiliki tekanan darah sistol dan diastol $<120 / 80 \mathrm{mmHg}$, prehipertensi $120-139 / 80-89 \mathrm{mmHg}$, hipertensi stage I $140-$ 159/90-99 mmHg, dan hipertensi stage $\| \geq 160 / 100 \mathrm{mmHg}$ [4]. Data dari profil kesehatan Provinsi Jawa tengah tahun 2017 menunjukkan sebanyak 24,2 persen warga Surakarta dinyatakan hipertensi/tekanan darah tinggi [5]. Penelitian ini bertujuan mengetahui korelasi kadar $\mathrm{COHb}$ terhadap tekanan darah pada penduduk di sekitar Terminal Bus Tirtonadi Surakarta dengan Spektrofotometer UV-Vis.

\section{Bahan dan Metode}

\subsection{Bahan}

Sampel dalam penelitian ini adalah darah dari 10 penduduk yang tinggal di sekitar Terminal Tirtonadi (Surakarta) yang tinggal lebih dari 3 tahun. Bahan kimia yang digunakan dalam penelitian ini antara lain $\mathrm{C}_{2} \mathrm{H}_{5} \mathrm{OH} 99,95 \%$ (Merck), $\mathrm{NH}_{4} \mathrm{OH} 25 \%$ (Merck), dan $\mathrm{Na}_{2} \mathrm{~S}_{2} \mathrm{O}_{4}$ (Emsure).

\subsection{Pemilihan Sampel}

Sampel dalam penelitian ini adalah sampel darah penduduk yang bertempat tinggal disekitar Terminal Tirtonadi yang memenuhi kriteria yaitu usia 15-64 tahun dengan lama tinggal lebih dari 3 tahun, tidak merokok aktif, mengkonsumsi garam dengan jumlah maksimal kurang lebih $5 \mathrm{~g}$ per hari, dan mempunyai waktu istirahat yang cukup (6-8 jam per hari). Penelitian didahului dengan sosialisasi, pengisian kuisioner, dan penandatanganan informed consent kepada calon responden. Responden yang memenuhi kriteria selanjutnya dilakukan pengambilan darah vena untuk pemeriksaan $\mathrm{COHb}$. Sampel darah yang didapat kemudian diperiksa kadar karboksihemoglobin di Laboratorium Kimia STIKES Nasional menggunakan Spektrofotometer UV-Vis (Shimadzu 1260 Mini) dan menggunakan metode Hinsberg-Lang. Pengukuran kadar CO di lingkungan dilakukan menggunakan alat $\mathrm{CO}$ meter untuk mengetahui kadar gas $\mathrm{CO}$ pada udara di lingkungan sekitar Terminal Tirtonadi. Pengukuran pada pukul 10.00-12.00 WIB di 4 titik lokasi dan dilakukan pada jam tersebut karena merupakan jam operasional bus dengan intensitas cukup tinggi di Terminal Tirtonadi Surakarta. Keempat titik lokasi pengukuran kadar CO di udara tersaji pada Gambar 1.

\subsection{Analisis Kadar Karboksihemoglobin dengan Metode Hinsberg-Lang}

Dua tabung reaksi diberi kode label R1 (reagen) dan SPL (reagen sampel). Sebanyak $20 \mathrm{~mL}$ larutan $\mathrm{NH}_{4} \mathrm{OH} 0,1 \%$ dimasukkan ke Erlenmeyer dan ditambahkan $10 \mu \mathrm{L}$ sampel darah lalu dihomogenkan. Larutan yang berada di erlenmeyer dipipet $4 \mathrm{~mL}$ kemudian masing-masing dimasukkan ke tabung R1 dan SPL. Sebanyak 20 mg Na${ }_{2} \mathrm{~S}_{2} \mathrm{O}_{4}$ ditambahkan ke dalam tabung SPL dan dihomogenkan. Campuran diinkubasi pada suhu $37^{\circ} \mathrm{C}$ selama 8 menit dan diukur absorbansi R1 dan SPL dengan Spektrofotometer UV-Vis pada panjang gelombang 414,2 nm [6]. Perhitungan kadar karboksihemoglobin $(\mathrm{COHb})$ menggunakan Persamaan 1.

$$
\text { Kadar } \mathrm{COHb}=\frac{\Delta \mathrm{A}}{\Delta \mathrm{ArHb}} \times 6,08 \%
$$


Dimana $\triangle \mathrm{A}$ adalah absorbansi reagen, $\Delta \mathrm{Ar} \mathrm{Hb}$ adalah absorbansi standar sampel dan 6,08 adalah faktor konversi persen saturasi CO dalam $\mathrm{Hb}$. Data yang diperoleh kemudian diuji normalitas data menggunakan SPSS uji Saphiro Wilk dan uji hipotesis menggunakan uji korelasi dengan nilai signifikan $=a<0,05$. Persentase peningkatan kadar $\mathrm{COHb}$ dihitung dengan Persamaan 2 dimana harga normal $\mathrm{COHb}$ adalah 3,5\%.

$$
\text { Presentase peningkatan kadar } \mathrm{COHb}=\frac{\text { Kadar } \mathrm{COHb}}{\text { Batas Normal } \mathrm{COHb}} \times 100 \%
$$

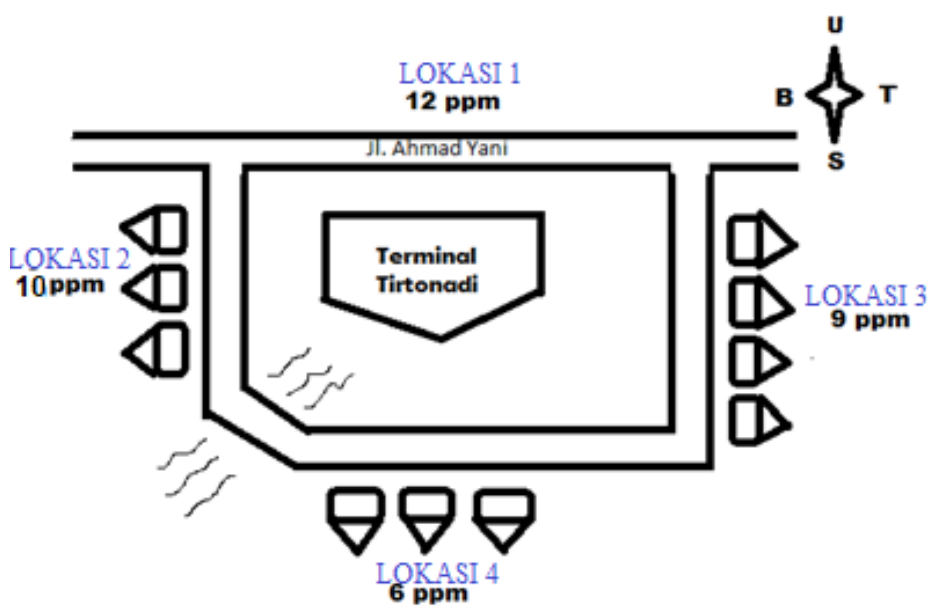

Gambar 1. Denah 4 titik lokasi pengukuran kadar CO di udara.

\section{Hasil dan Pembahasan}

Hasil penelitian korelasi kadar karboksihemoglobin $(\mathrm{COHb})$ terhadap tekanan darah pada penduduk yang tinggal di sekitar Terminal Tirtonadi Surakarta menunjukkan hasil kadar $\mathrm{COHb}$ pada seluruh responden lebih dari batas normal $\mathrm{COHb}$ yaitu 3,5\% dengan rata-rata peningkatan kadar $\mathrm{COHb}$ sebesar 77,63\%. Hasil penggukuran tekanan darah menunjukkan 4 responden memiliki tekanan darah diatas normal dalam kategori prehipertensi yaitu pada kode sampel A1, A2, A4 dan A8. Pengukuran kadar $\mathrm{COHb}$ seluruh responden didapatkan hasil lebih dari normal dengan rata-rata peningkatan kadar $\mathrm{COHb}$ sebesar 77,63\% (Tabel 1).

Tabel 1. Hasil Pengukuran Kadar $\mathrm{COHb}$ dan Tekanan Darah

\begin{tabular}{ccccc}
\hline Kode Sampel & Kadar $\mathbf{C O H b}(\%)$ & Sistol $(\mathbf{m m H g})$ & Diastol $\mathbf{( m m H g})$ & Persentase Peningkatan \\
\hline A1 & 6,51 & 130 & 80 & 86,00 \\
A2 & 6,28 & 120 & 80 & 79,43 \\
A3 & 6,22 & 110 & 70 & 77,71 \\
A4 & 6,23 & 130 & 80 & 78,00 \\
A5 & 6,21 & 100 & 70 & 77,43 \\
A6 & 6,17 & 110 & 70 & 76,29 \\
A7 & 6,17 & 100 & 60 & 74,57 \\
A8 & 6,11 & 130 & 80 & 75,71 \\
A9 & 6,15 & 110 & 70 & 74,86 \\
A10 & 6,12 & 110 & 70 & 77,63 \\
\hline Rata-rata & 6,22 & 115 & 73 & \\
\hline
\end{tabular}

Batas normal kadar $\mathrm{COHb}$ adalah 3,5\% [7] dan tekanan darah < 120/80 mmHg [4]

Standar deviasi pada uji statistik digunakan untuk menentukan bagaimana sebaran data dalam sampel dan seberapa dekat data individu ke rata-rata nilai sampel. Tabel 2 menunjukkan bahwa $\mathrm{COHb}$, sistol, dan diastol memiliki nilai penyimpangan data masing-masing sebesar 0,11538; 10,750 dan 6,749. Hasil rata-rata yang didapat yaitu kadar $\mathrm{COHb}$ sebesar 6,21\%; sistol sebesar $114 \mathrm{mmHg}$ dan diastol sebesar $73 \mathrm{mmHg}$. Pada Tabel 2 juga diperoleh hasil $p$ (nilai signifikan) untuk $\mathrm{COHb}$, sistol dan diastol berturut-turut sebesar 0,010; 0,177 dan 0,015. Berdasarkan data tersebut dapat dikatakan distribusi data bersifat tidak normal sehingga uji statistik yang digunakan adalah uji korelasi non parametrik Spearman. 
Tabel 2. Analisis Diskriptif Kadar $\mathrm{COHb}$ dan Tekanan Darah

\begin{tabular}{cccccc}
\hline & Standar Deviasi & Minimum & Maksimum & Rata-Rata & $\mathbf{P}$ \\
\hline $\mathrm{COHb}$ & 0,11538 & 6,11 & 6,51 & 6,21 & 0,010 \\
Sistol & 10,750 & 100 & 130 & 110 & 0,177 \\
Diastol & 6,749 & 60 & 80 & 70 & 0,015 \\
\hline
\end{tabular}

Tabel 3. Hasil Uji Korelasi Spearman Kadar $\mathrm{COHb}$ terhadap Tekanan Darah

\begin{tabular}{ccc}
\hline & $\mathbf{R}$ & $\mathbf{P}$ \\
\hline Kadar $\mathrm{COHb}$ & 1,000 & 0,000 \\
Sistol & 0,690 & 0,027 \\
Diastol & 0,756 & 0,011 \\
\hline
\end{tabular}

Tabel 3 menunjukkan bahwa nilai signifikan $(p)$ sebesar 0,027 dan 0,011 lebih kecil dari nilai a $(0,05)$ maka dapat disimpulkan bahwa terdapat korelasi kadar $\mathrm{COHb}$ dengan tekanan darah. Hasil analisis kadar $\mathrm{COHb}$ terhadap tekanan darah pada penduduk yang tinggal disekitar Terminal Tirtonadi Surakarta menunjukkan hasil kadar $\mathrm{COHb}$ pada seluruh responden lebih dari normal yaitu $>3,5 \%$. Hasil pengukuran kadar $\mathrm{CO}$ di udara lingkungan sekitar Terminal Tirtonadi dapat dilihat pada Tabel 4.

Tabel 4. Kadar CO di Udara Lingkungan Sekitar Terminal Tirtonadi

\begin{tabular}{lcc}
\hline & Jarak dari terminal (meter) & Kadar CO (ppm) \\
\hline Lokasi 1 (utara) & \pm 100 & 12 \\
Lokasi 2 (barat) & \pm 15 & 10 \\
Lokasi 3 (timur) & \pm 65 & 9 \\
Lokasi 4 (selatan) & \pm 55 & 6 \\
\hline \multicolumn{1}{c}{ Rata-rata } & & 9,25 \\
\hline
\end{tabular}

Hasil pengukuran yang tersaji dalam Tabel 4 dapat diketahui bahwa kadar CO di udara tertinggi adalah 12 ppm pada sisi bagian utara, sedangkan kadar terendah yaitu 6 ppm pada sisi bagian selatan. Empat lokasi Terminal Tirtonadi menyatakan bahwa kadar CO di udara dalam ambang batas normal. Menurut Mukono [8], udara yang mengandung CO sebesar 5-200 ppm dapat dikatakan sebagai udara tercemar. Penduduk yang tinggal disekitar Terminal Tirtonadi menghirup udara yang tercemar hampir setiap hari. Jarak rumah penduduk dengan Terminal Tirtonadi 15-100 m dan seluruh responden sudah lebih dari 3 tahun tinggal disekitar Terminal Tirtonadi.

Berdasarkan penelitian yang dilakukan oleh Rahayu dan Sudarmadji [9], konsentrasi $\mathrm{CO}$ ambien yang paling tinggi di wilayah Surakarta sebesar 9,25 ppm dan dapat berpotensi menjadi $\mathrm{COHb}$ dalam darah sebesar 1,477\%. Paparan gas $\mathrm{CO}$ dalam jumlah yang tinggi dengan waktu paparan menahun dapat meningkatkan kadar $\mathrm{COHb}$ di dalam darah [10]. Kondisi ventilasi juga mempengaruhi kadar $\mathrm{CO}$ di dalam rumah. Sebagian besar rumah responden memiliki ventilasi yang buruk. Rumah dengan ventilasi buruk akan mengakibatkan akumulasi gas $\mathrm{CO}$ di dalam rumah. Ventilasi yang tidak cukup akan menyebabkan kelembapan udara dalam ruangan naik karena terjadinya proses penguapan cairan dari kulit [8].

Patofisiologi keracunan gas $\mathrm{CO}$ yaitu ketika gas $\mathrm{CO}$ masuk ke paru-paru inhalasi, mengalir ke alveoli kemudian masuk ke aliran darah. Gas $\mathrm{CO}$ dalam darah akan berikatan dengan hemoglobin membentuk $\mathrm{COHb}$. Ikatan $\mathrm{COHb}$ yang kuat akan menyebabkan terhambatnya pengikatan hemoglobin dengan oksigen dalam darah [11]. Konsentrasi $\mathrm{COHb}$ yang meningkat dalam darah mengakibatkan peningkatan kekentalan darah sehingga mempermudah penggumpalan darah dan terjadinya vasokonstriksi (penyempitan pembuluh darah).

Vasokonstriksi pembuluh darah mengakibatkan aliran darah dari jantung ke seluruh tubuh menjadi terhambat sehingga menyebabkan peningkatan tekanan darah [9]. $\mathrm{COHb}$ dalam darah pada seseorang semakin tinggi, jika semakin lama terpapar gas $\mathrm{CO}$, hal ini mengakibatkan proses transpor oksigen ke jaringan tubuh terganggu. Darah tidak dapat menjalankan fungsinya sebagai alat transport oksigen ke jaringan tubuh, hal tersebut menyebabkan hipoksemia. Kondisi hipoksemia berisiko meningkatkan denyut jantung, tekanan sistolik, dan curah jantung [12]. Umur seseorang juga merupakan salah satu faktor kerentanan individu. Penurunan kapasitas kardiovaskuler karena proses menua dan berkurangnya fungsi elastisitas jaringan paru-paru mengakibatkan seseorang akan semakin rentan terhadap paparan CO sehingga kadar $\mathrm{COHb}$ akan semakin tinggi [13]. 


\section{Kesimpulan}

Hasil analisis kadar $\mathrm{COHb}$ terhadap tekanan darah pada penduduk yang tinggal disekitar Terminal Tirtonadi Surakarta menunjukkan hasil kadar $\mathrm{COHb}$ pada seluruh responden lebih dari normal yaitu $>3,5 \%$. Paparan gas $\mathrm{CO}$ di sekitar Terminal Tirtonadi memiliki kadar rata-rata sebesar $9,25 \mathrm{ppm}$. Gas CO yang dihirup oleh warga yang tinggal di sekitar Terminal Tirtonadi dalam waktu minimal 3 tahun dapat menimbulkan kenaikan kadar $\mathrm{COHb}$ dengan rata- rata sebesar $77,63 \%$, dimana 4 responden masuk dalam kategori prehipertensi yaitu pada kode sampel A1, A2, A4 dan A8. Setelah data tekanan darah dan kadar $\mathrm{COHb}$ dianalisis menggunakan SPSS dapat disimpulkan terdapat korelasi antara kadar $\mathrm{COHb}$ terhadap tekanan darah pada penduduk sekitar Terminal Bus Tirtonadi Surakarta. Peneliti selanjutnya dapat menambahkan jumlah responden agar distribusi sampel menjadi homogen dan factor-faktor yang dapat dikendalikan untuk mengurangi faktor perancu.

\section{Daftar Pustaka}

[1]. Kementerian Lingkungan Hidup dan Kehutanan, Pedoman Teknis Penyusunan Inventarisasi Emisi Pencemar Udara di Perkotaan. Jakarta: Kementerian Lingkungan Hidup dan Kehutanan, 2013.

[2]. C. D. Cooper \& F. C. Alley, Air Pollution Control: A Design Approach Fourth Edition. Illinois: Waveland Press, 2010.

[3]. R. Harrianto, Buku Ajar Kesehatan Kerja. Jakarta: EGC, 2010.

[4]. P. K. Whelton et al., "2017 ACC/AHA/AAPA/ABC/ACPM/AGS/APhA/ASH/ASPC/NMA/PCNA Guideline for the Prevention, Detection, Evaluation, and Management of High Blood Pressure in Adults: A Report of the American College of Cardiology/American Heart Association Task Force on Clinical Practice Guidelines," Hypertension, vol. 71, no. 6, pp. e13-e115, 2018.

[5]. Dinas Kesehatan Provinsi Jawa Tengah, Profil Kesehatan Provinsi Jawa Tengah Tahun 2015. Semarang: Dinas Kesehatan Provinsi Jawa Tengah, 2015.

[6]. F. L. Rodkey, T. A. Hill, L. L. Pitts, \& R. F. Robertson, "Spectrophotometric Measurement of Carboxyhemoglobin and Methemoglobin in Blood," Clinical Chemistry, vol. 25, no. 8, pp. 1388-1393, 1979.

[7]. Menteri Kesehatan Republik Indonesia, Peraturan Menteri Kesehatan Republik Indonesia Nomor 70 Tahun 2016 tentang Standar dan Persyaratan Kesehatan Lingkungan Kerja Industri. Jakarta: Kementerian Kesehatan, 2017.

[8]. H. J. Mukono, Pencemaran Udara dan Pengaruhnya terhadap Gangguan Saluran Pernapasan. Surabaya: Airlangga University Press, 2008.

[9]. M. Rahayu \& S. Sudarmadji, "Pemetaan Sebaran Karbon Monoksida Ambien dan Potensi Karboksihemoglobin $(\mathrm{COHb})$ dalam Darah di Wilayah Kota Surakarta," Jurnal Bumi Indonesia, vol. 2, no. 1, pp. 50-58, 2013.

[10]. M. Khairina, "The Description of CO Levels, COHb Levels, and Blood Pressure of Basement Workers X Shopping Centre, Malang," Jurnal Kesehatan Lingkungan, vol. 11, no. 2, pp. 150-157, 2019.

[11]. F. S. Noor, "Perbandingan Uji Alkali Dilusi dengan Uji Formalin pada Darah Tikus Wistar Setelah Terpapar Asap Knalpot dengan Kadar CO 1800 ppm Selama 4 Jam," Tesis, Universitas Diponegoro, Semarang, 2009.

[12]. A. R. Tualeka, Toksikologi Industri dan Risk Assessment. Surabaya: Graha Ilmu Mulia, 2013.

[13]. D. R. Pratiwi, H. Suryono, \& D. Nurmayanti, "Gambaran Kadar HbCO dalam Darah pada Masyarakat Dusun Gemeling, Gedangan, Sidoarjo," GEMA Kesehatan Lingkungan, vol. 16, no. 1, pp. 60-72, 2018. 